\title{
SOCIALIZANDO O DIREITO E FORMANDO PARA A CIDADANIA: UM RELATO DE EXPERIÊNCIA EXTENSIONISTA
}

\section{SOCIALIZING LAW AND FORMING FOR CITIZENSHIP: AN EXTENSIONIST EXPERIENCE REPORT}

Francisco Cavalcante de Sousa Maria de Fátima Lopes da Silva

\section{RESUMO}

A Constituição Federal do Brasil preconiza a educação como direito de todos e como incentivo a colaboração social visando o pleno desenvolvimento da pessoa em seu preparo para o exercício da cidadania (BRASIL, 1988). Por isso, a educação jurídica constitui-se como ação integrada no processo formativo para o exercício das profissões do Direito, assim como alicerce para construção de cidadãos antenados aos processos democráticos e para o exercício da própria cidadania. Ocorre que a educação jurídica ainda enfrenta muitos desafios para se consolidar nas escolas brasileiras em vista de seu linguajar dogmático e técnico-jurídico, que infelizmente continua restrito aos cursos de Direito. Para amenizar tal problemática, o Projeto de Extensão "Socializando o Direito", vinculado à Faculdade de Direito da Universidade do Estado do Rio Grande do Norte (UERN) surgiu para promover a educação jurídica sobre temas transversais e cotidianos nas escolas públicas de Mossoró/RN, visando estimular os discentes de escola pública a participarem cada vez mais dos anseios da comunidade. Por meio da experiências acadêmicas e extensionistas vivenciadas pelos integrantes do projeto, este trabalho tem como objetivo destacar a importância da educação jurídica calcada no exercício da cidadania e mensurar as contribuições advindas com o Projeto de Extensão "Socializando o Direito", principalmente no que tange a direitos fundamentais, combate à violência, participação política e responsabilidade cidadã.

Palavras-chave: Cidadania. Direito. Educação Jurídica. Extensão Universitária. Relato de experiência.

\section{ABSTRACT}

The Federal Constitution of Brazil provides for education as a right for all and as an incentive for social collaboration aimed at the full development of the person in his / her preparation for the exercise of citizenship (BRASIL, 1988). For this reason, legal education is an integrated action in the training process for the exercise of the legal professions, as well as a foundation for building citizens tuned in to democratic processes and for the exercise of citizenship itself. It turns out that legal education still faces many challenges to consolidate itself in Brazilian schools in view of its dogmatic and technical-legal language, which unfortunately remains restricted to law courses. To alleviate this problem, the Extension Project "Socializing the Law", linked to the Faculty of Law of the State University of Rio Grande do Norte (UERN) was created to 
promote legal education on transversal and everyday themes in public schools in Mossoró, Rio Grande do Norte State, aiming to encourage public school students toparticipate more and more in the community's wishes. Through the academic and extension experiences lived by the members of the project, this work aims to highlight the importance of legal education based on the exercise of citizenship and measure the contributions arising from the Extension Project "Socializing the Law", mainly with regard to fundamental rights, combating violence, political participation and citizen responsibility.

Keywords: Citizenship. Right. Legal Education. University Extension. Experience report.

\section{INTRODUÇÃO}

A Constituição Federal do Brasil de 1988, em seu artigo 205, preconiza a educação como direito de todos e como dever do Estado e da família, sendo incentivo para colaboração social visando o pleno desenvolvimento da pessoa em seu preparo para o exercício da cidadania (BRASIL, 1988). Nessa perspectiva, a educação jurídica constitui-se como ação integrada no processo formativo para o exercício das profissões do Direito, assim como alicerce para construção de cidadãos antenados aos processos democráticos e, de maneira geral, para o exercício da própria cidadania.

Porém, não se pode restringir a educação jurídica apenas aos cursos de Direito, pois nada adianta uma formação voltada à Ciência do Direito sem uma formação voltada para a cidadania e calcada em valores democráticos; mas sim, deve-se romper o linguajar essencialmente dogmático e restritivo dessa seara e disseminá-los para diferentes públicos, uma vez que estes também são responsáveis socialmente. Nesse sentido, surge como um dos primeiros desafios das faculdades de Direito romper o bloqueio entre o cidadão comum e o meio jurídico por meio de ações integradas de caráter científico, sociocultural e acadêmico.

Uma das estratégias adotadas é o Projeto de Extensão "Socializando o Direito", vinculado à Faculdade de Direito da Universidade do Estado do Rio Grande do Norte (UERN), Campus Universitário Central, Mossoró/RN. O projeto surgiu como uma alternativa a ser desenvolvida extra-Universidade para promover a educação jurídica sobre temas transversais e cotidianos nas escolas públicas, visando estimular os discentes de escolas locais a participarem cada vez mais dos anseios da comunidade, haja vista a importância do indivíduo engajar-se nas esferas públicas da vida democrática (MOUFFE, 1996.p. 83).

Desta feita, o presente trabalho busca demonstrar que a educação jurídica está diretamente atrelada a uma formação para cidadania e permite ao cidadão adquirir conhecimento sobre seus direitos e deveres, de modo que com o acesso à temáticas jurídicas, é possível proporcionar uma maior visibilidade para a importância da luta pelos direitos e exercício dos deveres, além de uma maior efetivação do acesso à justiça, responsabilidade cidadã e participação democrática.

Nessa conjuntura, considera-se que a extensão universitária alinhada à educação jurídica constituem-se como instrumentos importantes para popularização das temáticas relativas ao Direito, 
contribuindo de forma significativa para formação para a democracia e, de maneira mais difusa, para a cidadania. Por isso, o trabalho pretende destacar a importância da educação jurídica calcada no exercício da cidadania para, em seguida, tecer considerações sobre as experiências e contribuições advindas com o Projeto de Extensão "Socializando o Direito".

\section{A IMPORT ÂNCIA DA EDUCAÇÃOJURÍDICA VOLTADA AO EXERCÍCIO DA CIDADANIA}

A educação para a cidadania surge como contribuição para a formação de pessoas responsáveis, autônomas, solidárias, que conhecem e exercem os seus direitos e deveres em diálogo e no respeito pelos outros, com espírito democrático, pluralista, crítico e criativo, tendo como referência os valores dos direitos humanos (REPÚBLICAPORTUGUESA, 2012).

Na Constituição brasileira de 1988, a educação é assegurada como direito de todos e dever do Estado e da família visando o preparo para o exercício da cidadania e sua qualificação para o trabalho, como preconiza o art. 205:

Art. 205. A educação, direito de todos e dever do Estado e da família, será promovida e incentivada com a colaboração da sociedade, visando ao pleno desenvolvimento da pessoa, seu preparo para o exercício da cidadania e sua qualificação para o trabalho.

A Lei de Diretrizes e Bases da Educação (LDB), Lei n ${ }^{0}$ 9.394, de 20 de dezembro de 1996, em seu Art. 26, § 9 determina a presença de conteúdos relativos aos direitos humanos e à prevenção de todas as formas de violência contra a criança e o adolescente, como temas transversais, nos currículos escolares (BRASIL, 1996), tendo como diretriz o Estatuto da Criança e do Adolescente (ECA), instituído pela Lei $n^{\circ}$ 8.069, de 13 de julho de 1990 (BRASIL, 1990).

Por sua vez, o ECA traz em seu art. $3^{\circ}$ a proteção integral das crianças e dos adolescentes sem discriminação de nascimento, situação familiar, idade, sexo, raça, etnia ou cor, religião ou crença, deficiência, condição pessoal de desenvolvimento e aprendizagem, condição econômica, ambiente social, região e local de moradia ou outra condição que diferencie as pessoas, as famílias ou a comunidade em que vivem (BRASIL, 1990), haja vista que a educação têm de responder às necessidades de toda a gente.

Ocorre que a educação jurídica ainda enfrenta muitos desafios para se consolidar nas escolas brasileiras, tendo em vista o seu linguajar essencialmente dogmático e técnico-jurídico, que continua restrito aos cursos de Direito. Por consequência, esse cenário dificulta a transmissão dos conhecimentos ao público em geral, principalmente aos que não tiveram acesso a uma educação básica de qualidade, e interfere no desenvolvimento de uma formação sócio- educacional para questões democráticas e cidadãs.

Tal contexto evidencia que a educação, tanto formal quanto informal, exerce papel primordial para formação de pessoas em sociedades democráticas, fomenta o desenvolvimento das liberdades individuais e coletivas e contribui para um avanço civilizatório em contextos multiculturais. Mister enfatizar que a educação para cidadania engloba temas transversais que versam, entre outros assuntos, sobre direitos 
humanos, minorias étnico-raciais, gêneros, responsabilidade social, entre outros assuntos.

Esse processo de aprendizagem que prioriza a transversalidade e a interdisciplinaridade corrobora para tomada de consciência e transformação social de determinada comunidade onde os cidadãos estão inseridos, transformando o espaço baseado nos valores da igualdade, democracia e justiça. Nas diretrizes educacionais de Portugal, a título de exemplo, considera- se que:

\begin{abstract}
A prática da cidadania constitui um processo participado, individual e coletivo, que apela à reflexão e à ação sobre os problemas sentidos por cada um e pela sociedade. $\mathrm{O}$ exercício da cidadania implica, por parte de cada indivíduo e daqueles com quem interage, uma tomada de consciência, cuja evolução acompanha as dinâmicas de intervenção e transformação social. A cidadania traduz-se numa atitude e num comportamento, num modo de estar em sociedade que tem como referência os direitos humanos, nomeadamente os valores da igualdade, da democracia e da justiça social (REPÚBLICAPORTUGUESA, 2012).
\end{abstract}

Algumas discussões acerca da função educacional no contexto das democracias têm destacado a necessidade dos sistemas educacionais de todo o mundo incluírem em seus currículos atividades com dimensão formativa para os valores republicanos e democráticos, assim como para a formação e tomada de decisões políticas em todos os níveis, desde o ensino fundamental ao ensino superior.

Benevides (1996) defende a educação como instrumento para a democracia em contextos sociopolíticos e como meio para maior participação dos cidadãos nas decisões políticas, pois uma maioria é comandado por um grupo minoritário tomador de decisões. Entretanto, surge como necessário no século XXI que essa maioria seja conhecedora e participativa, "pois numa sociedade verdadeiramente democrática ninguém nasce governante ou governado, mas pode vir a ser, alternativamente - e mais de uma vez no curso da vida - um ou outro"(BENEVIDES, 1996, p. 226).

Ainda, a Câmara de Ensino Superior do Conselho Nacional de Educação, em 17 de dezembro de 2018, publicou a Resolução CNE/CES n. ${ }^{\circ}$ 5/2018 que instituiu as Diretrizes Curriculares Nacionais do Curso (DCNs) de Graduação em Direito, a qual nos diz em seu art. $2^{\circ}, \S 1^{\circ}$, inciso IX, que no Projeto Pedagógico do Curso (PPC) deverá constar, alguns elementos estruturais, dentre eles o incentivo, de modo discriminado, à pesquisa e à extensão, como fator necessário ao prolongamento da atividade de ensino e como instrumento para a iniciação científica.

Ademais, o art. $2^{\circ}, \S 4^{\circ}$ da Resolução CNE/CES n. ${ }^{\circ}$ 5/2018 nos diz que o PPC deve prever ainda as formas de tratamento transversal dos conteúdos exigidos em diretrizes nacionais específicas, tais como as políticas de educação ambiental, de educação para a terceira idade, de educação das relações étnico-raciais, de educação em direitos humanos, entre outros.

Tais temas são importantes para adoção de uma visão de mundo do discente de forma sistêmica e integrada de conhecimentos e práticas que congregam diferentes saberes, transcendendo as noções de disciplina e de área (RODRIGUES, 2019, p. 85). Deve-se assim, buscar um processo de ensino- 
-aprendizagem plenamente eficaz em sua dinâmica formativa, afastando desse processo às atividades meramente informativas do ensino, pois o papel do sistema educativo não é só informar, mas especialmente, formar(RODRIGUES, 2019, p. 73).

\section{O PROJETO DE EXTENSÃO "SOCIALIZANDO O DIREITO"}

Frente a essa contextualização da formação para a cidadania, convém destacar que as experiências acadêmicas advindas com o projeto de extensão "Socializando o Direito”, da Faculdade de Direito da UERN, têm mostrado que a extensão universitária representa uma das maneiras de promover uma educação voltada para a cidadania e para a democracia, tendo os estudantes de graduação e ensino médio como protagonistas no processo extensionista.

De maneira geral, o projeto trata-se de um conjunto de atividades integradas de caráter social, cultural e educativo/científico, buscando dilacerar o bloqueio existente entre o cidadão comum e o meio jurídico e levando aos alunos que estudam em escolas públicas, as noções basilares do conhecimento do Direito (UERN, 2018).

Ou seja, os discentes são estimulados a "transformar" o mundo que os cerca. Tal tema é tão importante que o Relatório para a Organização das Nações Unidas para a Educação, a Ciência e a Cultura (UNESCO), da Comissão Internacional sobre Educação para o século XXI (DELORS,s. d.), traz como um dos quatro pilares da Educação, o "aprender a fazer", transformando o mundo que o cerca, com os conhecimentos adquiridos.

O projeto leva a comunidade temáticas relacionadas ao Direito, cidadania, educação jurídica e participação social, oportunizando aos discentes, atividades complementares de formação profissional, humana e cidadã, de modo que possam contribuir concreta e diretamente com a vida em sociedade, em especial dos alunos de escolas públicas de Mossoró/RN.

Sendo assim, os graduandos utilizam-se dessa iniciativa para desenvolver uma série de debates e palestras com temas como direitos fundamentais, combate à violência, participação política, responsabilidade cidadã, etc., de modo que os alunos de escola pública que participarem como ouvintes, terão conhecimento dos direitos e garantias nesses casos e saberão como agir, inclusive de maneira preventiva, difundindo os conhecimentos ali adquiridos, ou seja, fortalecendo as capacidades de todos na rede de proteção contra as crianças e os adolescentes.

A experiência enquanto integrantes do projeto de extensão "Socializando o Direito" permite transgredir o espaço universitário e chegar a comunidades com contextos de vulnerabilidade social, oportunizando conhecer as reais necessidades ambientais dos cidadãos. Nessa perspectiva, é possível transformar as teorias aprendidas na sala de aula da Universidade em conhecimentos significativos, permitindo uma melhor formação acadêmica e profissional e buscando contribuir para a superação das desigualdades sociais existentes nas comunidades impactadas pela iniciativa. 
Vale salientar também que os métodos diferenciados de ensino-aprendizagem são responsáveis por uma maior interação entre aluno e professor (ou no caso em específico, aluno e palestrante), visando a construção de um processo sócio construtivo com interesse maior por parte do ouvinte. Por parte dos próprios discentes do curso de Direito, o projeto torna-se um meio de aproximá-los da docência, despertando o interesse pela área, e intensificando o interesse daqueles que já têm o objetivo de segui-la.

\section{EXPERIÊNCIAS ACADÊMICAS E EXTENSIONISTAS COMO CONCRETIZADORAS DA FORMAÇÃO PARA CIDADANIA}

É importante colocar que o primeiro contato com o público-alvo do projeto foi uma oportunidade para se ter uma ideia geral de como, na prática, o projeto "Socializando o Direito" se concretiza, pois o principal obstáculo enfrentado foi dilacerar o bloqueio existente entre o aluno de escola pública e o conteúdo jurídico ministrado.

Assim, as atividades do projeto iniciaram-se com a temática do direito à educação na Escola Municipal Dinarte Mariz (Fotografia 2) no dia 11 de julho de 2018, e de imediato, percebeu-se a dinâmica estabelecida entre os estudantes de graduação da universidade com os alunos da escola (Fotografia 2). Dessa forma, esta interação proporcionou aos extensionistas do projeto uma dimensão das carências enfrentadas por essa população mais vulnerável da sociedade no concerne ao direito fundamental à educação, isto é, justamente aquela parte que carece de informação no tange à direitos básicos, bem como as dificuldades quanto a estratégias para efetivá-los.

Com base nisso, as exposições foram focadas em socializar conhecimentos para o exercício da cidadania, tendo em vista ser, ainda, uma deficiência considerável enfrentada por inúmeras crianças e adolescentes e pela própria escola que, muitas vezes, não dispõe de formações para que possam trabalhar tais temáticas na sala de aula. Desse modo, a palestra sobre direito à educação destacou o papel primordial da escola como recurso para formação de pessoas, respeito às diferenças e direitos humanos e contribuição para um avanço civilizatório em contextos multiculturais.

A palestra "Participação Política através do direito de reunião e a questão das passarelas na BR 304" foi realizada no dia 20 de setembro de 2018 na Escola Estadual Profa. Maria Stella Pinheiro Costa (Fotografia 3), que, por sua vez, estava situada próximo à uma rodovia federal bastante movimentada e sem passarela em suas imediações. Tal contexto representava um risco palpável a integridade das pessoas que passam por ali, em especial dos estudantes, pois, estes precisavam atravessar a rodovia diariamente para chegar até a escola, já que muitos dos alunos moram depois da pista.

Na prática, essa realidade é um obstáculo à própria locomoção dos estudantes e ao seu devido exercício ao direito à educação. Assim, nesta palestra mostrou-se de maneira lúdica através de recursos visuais como charges, tirinhas e brincadeiras múltiplas formas de participação para a resolução do problema próximo à escola, isto é, pressionando as autoridades através da participação em audiências públicas, assim 
como, no exercício do direito de reunião e do voto, dentre outros. Essa atividade destacou o fomento as habilidades necessárias para promover a justiça social nas nações (BANKS, 2008), pois prepara o cidadão para agir de forma consciente, como parte de uma estrutura coletiva (WERNER, 2017).

Outra experiência significativa foi a que trabalhou-se sobre direito das minorias com alunos de idades entre 8 e 15 anos, dentro do Projeto Social SESC Cidadão no dia 29 de março de 2019 (Fotografia 4). Nesta ocasião, os extensionistas do projeto "Socializando o Direito" exploraram sobre o tema "Direito das Minorias: idosos, mulheres e deficientes", buscando reforçar a ideia de respeito às diferenças e da necessidade a tolerância no ambiente escolar, tendo como foco uma educação voltada para o respeito aos direitos humanos, em conformidade com a Lei de Diretrizes e Bases da Educação (LDB), Lei n ${ }^{\circ}$ 9.394, especialmente seu art. $26, \S 9$.

Por meio da palestra foi possível levar a escola conteúdo de natureza participativa, onde os estudantes são incentivados a refletirem sobre o contexto em que estão inserido, bem como são motivados para a tomada de decisões políticas e reivindicações sociais (NETO, 2017), buscando promover a justiça social (BANKS, 2008) através de exemplificações cotidianas adaptadas ao ensino fundamental e agir de forma consciente e em cidadania com os colegas (WERNER, 2017).

$\mathrm{Na}$ palestra sobre educação ambiental e responsabilidade cidadã realizada na Escola Estadual Jerônimo Rosado no dia 6 de agosto de 2019 (Fotografia 5), os membros do Projeto discorreram sobre a problemática ambiental contemporânea e as principais atividades que contribuem para sua expansão global e enfatizaram o nosso papel enquanto sujeito de direitos e deveres na pauta ambiental atual. Entre os pontos abordados, esteve o histórico das questões ambientais (surgimento, crescimento populacional, revolução industrial, poluição), uma contextualização sobre os direitos transindividuais e difusos como direitos de terceira dimensão/geração, os dispositivos da CF/88 que garantem o direito ecologicamente equilibrado, principalmente o art. $225, \S 1^{\circ}$, inciso VI, que trata da Educação ambiental como direito em todos os níveis de ensino visando a conscientização pública para a preservação do meio ambiente, a Lei n ${ }^{\circ} 9.795$, de 27 de abril de 1999.

Destacou-se a relevância de falar sobre educação ambiental e responsabilidade cidadã atualmente, o papel das empresas na pauta ambiental e os instrumentos jurídicos de proteção e participação do cidadão nos processos democráticos, como ação civil pública, participação em audiências públicas, ciberativismo, acompanhamento dos portais governamentais, realização de proposições legislativas, entre outras.

\section{CONSIDERAÇÕES FINAIS}

Por meio do Projeto de Extensão "Socializando o Direito" pode-se constatar que a participação na extensão universitária contribui significativamente para a formação dos estudantes do Curso de Direito, assim como dos alunos das escolas públicas que são atendidos pelo Projeto, os quais terão consciência do poderdever de influência do cidadão nos rumos estatais, e tal senso de dever, bem como o dever de cumprir esses deveres, nasce com a própria educação voltada para democracia (BOBBIO, 2007). 
Além disso, o Projeto de Extensão "Socializando o Direito" oportuniza o desenvolvimento do espírito de equipe e capacidade de interação com o público-alvo de sua ação e de compartilhamento de tarefas, iniciativa e protagonismo, bem como demonstração de responsabilidade, dedicação e organização, qual seja, objetivando levar conhecimento jurídico de qualidade, de maneira clara e objetiva, para os alunos de escolas públicas. Desta feita, nos parece que as informações transmitidas pelo Projeto de extensão são primordiais para efetivação da educação para democracia, através do fomento as habilidades necessárias para promover a justiça social nas nações (BANKS, 2008), pois prepara o cidadão para agir de forma consciente, como parte de uma estrutura coletiva (WERNER, 2017), bem como motiva a tomada de decisões políticas (NETO, 2017).

Desse modo, a experiência enquanto integrantes do Projeto de Extensão "Socializando o Direitos" permite transgredir o espaço universitário e chegar a comunidades com contextos de vulnerabilidade social, oportunizando conhecer as reais necessidades dos cidadãos. Nessa perspectiva, é possível transformar as teorias aprendidas na sala de aula da Universidade em conhecimentos significativos, permitindo uma melhor formação acadêmica e profissional e buscando contribuir para a superação das desigualdades sociais existentes nas comunidades impactadas pela iniciativa e tornar a Universidade um espaço socialmente referenciado.

Além de formar cidadãos críticos, o referido Projeto torna acessível o conhecimento sobre o Direito às pessoas de pouco poder aquisitivo, carentes de assistência não somente material, mas também intelectual, no aspecto de conhecimentos sobre os seus direitos e deveres, de modo que as palestras realizadas pelo Projeto de Extensão "Socializando o Direito" contribuíram significativamente para democratização do conhecimento jurídico nas escolas públicas atendidas em Mossoró/RN, principalmente quanto às noções de Educação Ambiental, responsabilidade cidadã, participação política, Estatuto da Criança e do Adolescente, Direitos sociais e, consequentemente, uma abordagem acerca da educação pautada em práticas democráticas e cidadãs.

Considera-se que deve-se buscar o estímulo para que as Faculdades de Direito tenham maior número de Projetos de Extensão que objetivem levar aos estudantes de escolas públicas noções jurídicas e de cidadania, através de atividades integradas de caráter social, cultural, científico e educativo, haja vista que a educação para os valores democráticos, trata-se de "patrimônio ético-jurídico da humanidade" (NETO, 2017).

Desta feita, haverá um ganho tanto do aluno do curso de Direito como cidadão, ao aproximá-lo dos anseios sociais destes alunos de escola pública, formados pelos mais diversos grupos sociais, étnicos, culturais, religiosos, políticos etc., de modo que haverá uma preocupação não só com a educação para cidadania, mas a educação para uma democracia plural em busca de um verdadeiro Estado democráticoparticipativo (BONAVIDES, 2003).

Restou evidente assim, que o direito à educação é um dos 'empowerment rights' (direitos de empoderamento), pois é através do direito à educação que o indivíduo terá o controle sobre o curso de sua 
vida, bem como possibilitará o benefício de outros direitos e liberdades (COOMANS, s. d.).

Ademais, o aluno de escola pública também é beneficiado, pois será motivado a ser mais atuante na efetivação dos direitos fundamentais assegurados pelo Estado Democrático de Direito, sendo assim, capaz de difundir seus ideais e organizar-se em prol de seus direitos (OWARD-HASSMANN; DONNELLY, 1988).

De maneira geral, evidencia-se que o diálogo entre experiências acadêmicas e extensão universitária resulta em um processo dinâmico e construtivo que concretiza a Educação Jurídica e promove uma formação para a cidadania pautada em práticas democráticas e cidadãs.

\section{REFERÊNCIAS BIBLIOGRÁFICAS}

BANKS, James A. Diversity, Group Identity, and Citizenship Education in a Global Age. Educational Researcher, v. 37,n. 3, p. 129-139, 2008.

BENEVIDES, M. V. M. Educação para a democracia. Lua Nova, São Paulo , n. 38, p. 223- 237, 1996. Disponivel em <http://www.scielo.br/scielo.php?script=sci_arttext\&pid=S010264451996000200011\&lng=en\&nrm=iso $>$. Acesso em 22/08/2019

BOBBIO, Norberto. Direitos e Deveres da República: os grandes temas da política e da cidadania. Rio de Janeiro: Campus, 2007.

BONAVIDES, Paulo. Teoria Constitucional da Democracia Participativa: por um Direito Constitucional de luta e resistência, por uma nova hermenêutica, por uma repolitização da legitimidade. 2 ed. São Paulo: Malheiros, 2003.

BRASIL. Constituição da República Federativa do Brasil, de 5 de outubro de 1988. Disponível em: http://www.planalto.gov.br/ccivil_03/Constituicao/Constituicao.htm. Acesso em 06 ago. 2019.

BRASIL. Lei n. ${ }^{\circ}$.394, de 20 de dezembro de 1996. Disponível em: http://www.planalto.gov.br/ccivil_03/leis/19394.htm. Acesso em 06 ago. 2019.

B R A S I . Lei n. ${ }^{\circ} 8.069$, de 13 de julho de 1990. Disponível e m: $<$ http://www.planalto.gov.br/ccivil_03/leis/18069.htm>.Acesso em 09 fev. 2020.

CONSELHO NACIONAL DE EDUCAÇÃO. Resolução CNE/CPn. ${ }^{\circ} \mathbf{1}$, de 30 de maio de 2012. Disponível em: <http://portal.mec.gov.br/dmdocuments/rcp001_12.pdf > . Acesso em 04 fev. 2020.

CONSELHO NACIONAL DE EDUCAÇÃO. Resolução CNE/CES n. ${ }^{\circ}$, de 17 de dezembrode 2018. Disponível e $\mathrm{m}$ http://portal.mec.gov.br/index.php?option=com_docman\&view=download\&alias=104111- rces00518\&category_slug=dezembro-2018-pdf\&Itemid=30192. Acesso em 20 jan. 2020.

COOMANS, Fons. Clarifying the Core Elements of the Right to Education. Disponível em: http://aihrresourcescenter.org/administrator/upload/documents/core.pdf. Acesso em 27 ago. 2019.

DELORS, Jacques et al. Educação: um tesouro a descobrir. Relatório para a UNESCO da Comissão Internacional sobre Educação para o século XXI. Disponível e m $<$ http://unesdoc.unesco.org/images/0010/001095/109590por.pdf>. Acesso: 26 abr. 2019.

MOUFFE, Chantal. O regresso do político: trajectos. Lisboa: Gradiva, 1996.

NETO, Luísa. Educação e(m) Democracia. Porto: U. Porto Editorial, 2015.

NETO, Luísa. Democracia, Cidadania e Pluralismo In MARTINS, Ana Gouveis; LEÃO, Anabela; CRORIE, Benedita Mac; MARTINS, Patricia Fragoso (Coord.). X Encontro de Professores de Direito Público. Lisboa: Ed. Instituto de Ciências Jurídico-Políticas, 2017. p. 266-296. 
OWARD-HASSMANN, R.; DONNELlY, J. Assessing National Human Rights Perfomance: a Theoretical Framework. Human Rights Quarterly, v. 10, n. 2, 1988.

REPÚBLICA PORTUGUESA. Direção-Geral da Educação. Educação para a cidadania - Linhas orientadoras. Lisboa, Portugal, 2012. Disponivel em https://dge.mec.pt/educacao- para-cidadania-linhasorientadoras-0. Acesso em 22/08/2019.

RODRIGUES, Horácio Wanderlei. Cursos de Direito no Brasil: diretrizes curriculares e projeto pedagógico. Florianópolis: Habitus, 2019.

UERN. Projetode Extensão Socializando o Direito. Disponível em: http://fad.uern.br/default.asp?item=fad\%20-\%20socializando\%20o\%20direito. Acesso em 02 ago. de 2019.

WERNER, Patrícia Ulson Pizarro. Regime constitucional da educação. Enciclopédia Jurídica da PUC SP. 2017.

Agradecimentos: Projeto de Extensão "Socializando o Direito" da Faculdade de Direito da UERN. 


\section{ANEXOS}

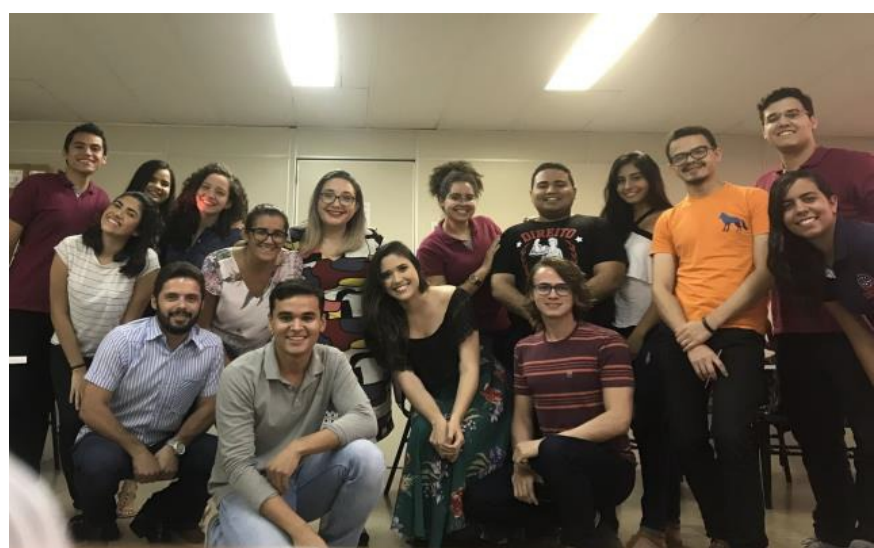

Fotografia 1. Reunião de planejamento das ações do projeto no ano de 2019

Fonte: FAD/UERN (2019)

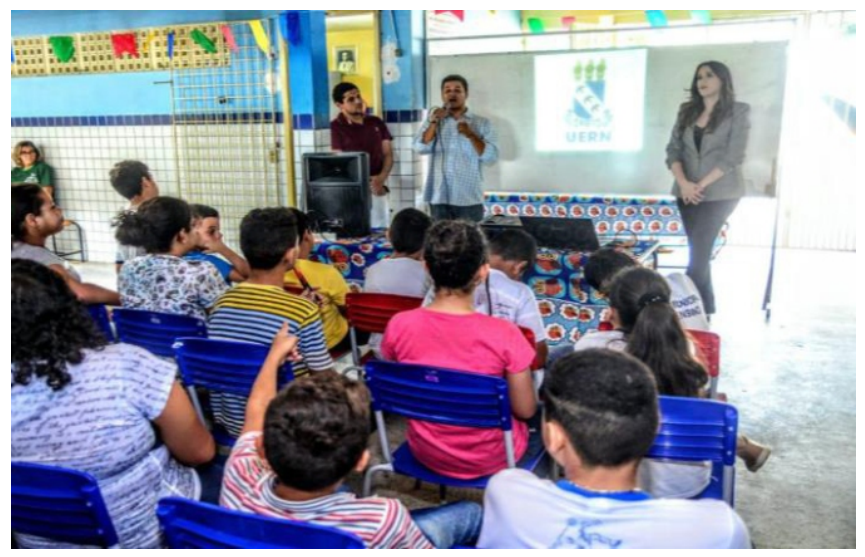

Fotografia 2. Encontro na Escola Municipal Dinarte Mariz com o tema "Direito à Educação"

Fonte: FAD/UERN (2018)

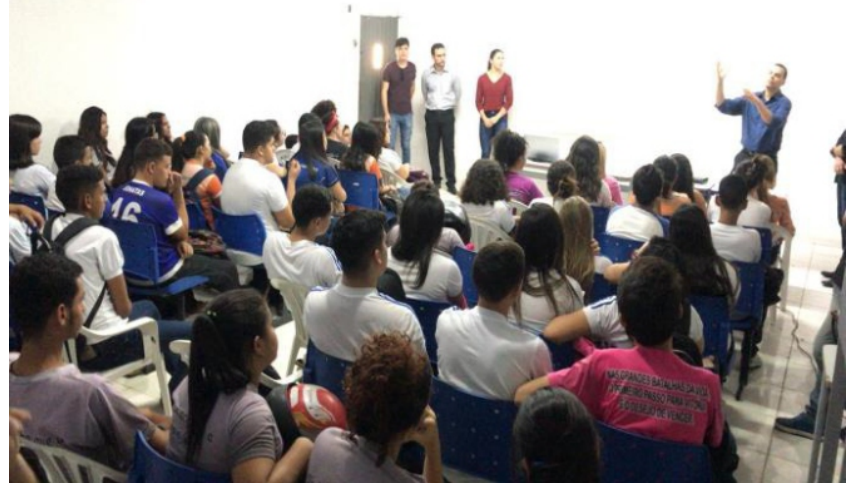

Fotografia 3. Encontro sobre "Participação Política através do direito de reunião e a questão das passarelas na BR 304" Fonte: FAD/UERN (2018)

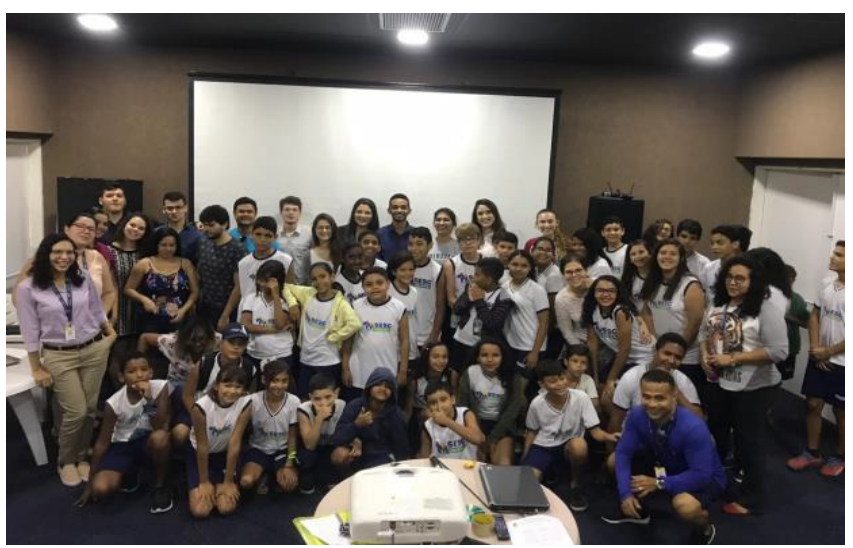

Fotografia 4. Palestra sobre Direito das minorias no Projeto SESC Cidadão Fonte: FAD/UERN (2019)

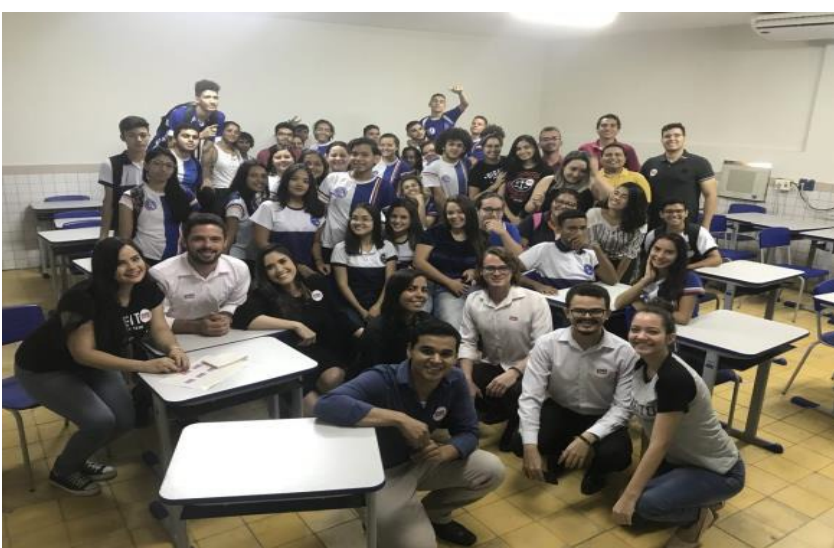

Fotografia 5. Encontro sobre Educação Ambiental e Responsabilidade Cidadã Fonte: FAD/UERN (2019) 